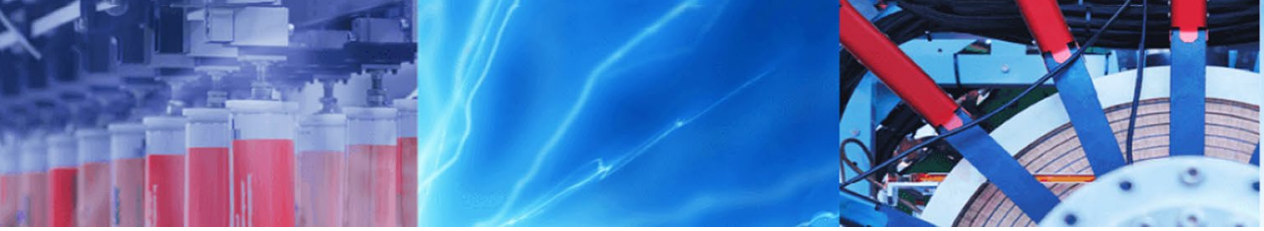

Research Article

\title{
Effects of bovine gelatin viscosity on gelatin-based edible film mechanical, physical and morphological properties
}

\author{
A. Sancakli ${ }^{1,2}$ (D) B. Basaran ${ }^{1} \cdot$ F. Arican $^{2} \cdot$ O. Polat $^{2}$
}

Received: 8 September 2020 / Accepted: 23 December 2020 / Published online: 6 January 2021

(C) The Author(s) 2021 OPEN

\begin{abstract}
This study was conducted to determine the effect of gelatin reology on mechanical, physical and morphological properties of gelatin-based edible films. The aim of this study was to better understand the variation of viscosity on the structural behaviour of gelatin-based films in the presence of glycerol and sorbitol plasticizers. Gelatin-based films were casted by using gelatins of different viscosities as 2.5, 3.0 and 3.5 centipoise with plasticisers as glycerol and sorbitol. Finally, the physical, mechanical and morphological properties of the films were investigated via $\mathrm{pH}$, thickness, tensile strength and elongation, fourier transform infrared spectroscopy and scanning electron microscopy. As a result of the study, it was observed that a durable film structure could be obtained with gelatin viscosity at 3 centipoise. Furthermore $5.5 \%$ gelatin, $0.1 \%$ glycerol and $0.4 \%$ sorbitol concentration were found as the most suitable formulation for gelatin based film structure with Tukey Test. The results suggest that gelatin-plastisizer combinations can be an excellent source of biobased packaging material with further investigations.
\end{abstract}

Keywords Gelatin · Plasticizer · Viscosity · Edible film · Food package · Biopolymer

\section{Introduction}

Plastic packaging materials are commonly used by food and beverage industry [1]. As it is known, the physical. structure of the package protects food from external effects with ideal cost and secure food protection. However, as a result of ammesment of tremendous amounts of petroleum-based plastic wastes in the environment. and also rapid dwindling of fossil reserves, food packaging industry is forced the toward the development of ecofriendly materials like bioplastics as a substitute of petroleum-based plastics [2]. Bioplastics can be called as plastics derive from renewable materials that are biocompostable and/or biodegradable materials [3, 4]. Bioplastic resources such as proteins (can be referred as gelatin and collagen) [5], polysaccharides [6], lipids [7], and their combinations have a huge potential to reduce plastic waste with development on new implementations.

With the use of bio-nanocomposites instead of petroleum-based packaging materials, significant progress can be made in terms of protecting the environment and human health in the future [8]. Gelatin and its composites can be used as a biodegradable material on food packaging due to their good film forming properties [9-12]. It is studied in the literature that; composite films obtained by using potato starch chicken gelatin have rheologically and mechanically stable properties [13], biodegradable film structures produced by using gelatin obtained from fish residues and glycerol were characterized [10], the potential applications of gelatin-based films on food packaging were investigated [14], nano-technological food packaging implementation methods were delevopled for fish gelatin-based

A. Sancakli, aykutsancakli@gmail.com | 'Department of Leather Engineering, Faculty of Engineering, Ege University, Bornova, Izmir 35100, Turkey. ${ }^{2}$ Kazlicesme R\&D Center and Test Laboratories, Tuzla, İstanbul, Turkey. 
biomaterials [15], bio-compatability of the gelatin based bio-polymers were examined [16] and the effect of drying temperatures on gelatin-based composite films were analysed [17].

Although a lot of research carried out on this subject, still not enough information to reveal the unique rheological properties of gelatin, as a result of the use of different plasticizers with varying ratios of the ability to form a gelatin-based film in integrity. In this study, it was aimed to investigate the effects of different gelatin viscosities on physical, mechanical and morphological properties such as thickness, tensile strength, elongation, surface morphology and chemical structure of gelatin based films plasticized with glycerol and sorbitol. With this work carried out; it may be possible to fill the information gap regarding the effect of the rheological properties of gelatin on the film structure, which has not been explained in detail in the literature.

For this purpose, gelatin-based films were casted using film solutions prepared with the RSM experimental modelling method. Then, physical, chemical, mechanical and morphological analyzes were applied to the films obtained. Additionally, the usability of the obtained films as food packaging was evaluated.

\section{Materials and methods}

\subsection{Materials and reagents}

Commercially available food-grade type B bovine gelatin was purchased from Halavet Jelatin (Turkey) in granule form, sorbitol (liquid) was provided by Sunar Mısır Entegre Tesisleri San. ve Tic. A.Ş (Turkey) and glycerol (liquid) was purchased from Sigma-Aldrich. Pure water and all chemicals used in this study were at least food grade.

For all gelatin samples, average molecular weight (MW) value is between $100.000-150.000 \mathrm{~g} / \mathrm{mol}$. Other technical spesifications of gelatin samples are given in Table 1.

Table 1 Technical specifications of gelatin samples

\begin{tabular}{lccc}
\hline Technical speficications & Gelatin 1 & Gelatin 2 & Gelatin 3 \\
\hline Jel strength (bloom) & $270 \pm 10$ & $240 \pm 10$ & $210 \pm 10$ \\
Viscosity (cP) & $3.50 \pm 0,1$ & $3.00 \pm 0,1$ & $2.50 \pm 0,1$ \\
Transmittance (\%) & $93.05 \pm 0,1$ & $97.37 \pm 0,1$ & $98.40 \pm 0,1$ \\
Moisture (\%) & $9.35 \pm 0,1$ & $9.65 \pm 0,1$ & $9.40 \pm 0,1$ \\
pH & $5.72 \pm 0,1$ & $5.71 \pm 0,1$ & $5.75 \pm 0,1$ \\
Isoelectric Point & $5,50 \pm 0,1$ & $5,45 \pm 0,1$ & $5,55 \pm 0,1$ \\
\hline
\end{tabular}

SN Applied Sciences

\subsection{Determination of gelatin and film solution viscosity}

Viscosity of gelatin and film solutions was determined according to the Gelatin manufacturers institute of America (GMIA) standard testing methods for edible gelatin [18]. According to the this method gelatin solution prepared with the solid matter content $6.67 \%$ at $60{ }^{\circ} \mathrm{C}$ temperature and results was reported in centipoise [19].

\subsection{Preparation of response surface methodology}

Response surface method (RSM) is a convenient technique in modelling and optimising a process through statistical and mathematical measures to disclose the correlation between process variables and outputs [20]. RSM experimental design was created by Minitab 17 software and variable used as follows; gelatin viscosity $(2.0,2.5$ and $3.0 \mathrm{cP})$, gelatin concentration $(1 \%, 5.5 \%$ and $10 \%)$, glycerol and sorbitol concentrations $(0.1 \%, 0.3 \%$ and $0.5 \%)$.

\subsection{Preparation of gelatin films}

In order to obtain biodegradable films, $100 \mathrm{ml}$ of pure water was measured using a pipette and placed into a 250-ml flask. Then, pre-weighed bovine gelatin concentrations $1 \%, 5,5 \%$ and $\% 10$ was added into the flask respectively. The gelatin mixture was allowed to stand for $30 \mathrm{~min}$. at room temperature to absorb water, swell and settle. The flask was then covered with aluminium foil before placing it into a water bath set at $60^{\circ} \mathrm{C}$. The gelatin was completely dissolved for $30 \mathrm{~min}$ by shaking the mixture occasionally. In accordance with the RSM experimental design, glycerol and/or sorbitol $(0.1 \%$, $0.3 \%$ and $0.5 \%$ ) was added to the completely dissolved gelatin using a pipette. The solution was shaken in the water bath set at $60^{\circ} \mathrm{C}$. Polystyrene moulds were used for casting. The casted films were dried for $24 \mathrm{~h}$ in an oven heated to $45^{\circ} \mathrm{C}$ [21]. This temperature value was chosen because film solution maintains its liquid form at temperatures above its melting point, herewith material can reach high concentrations. Gel formation is avoided because the rate of drying is faster than the rate of nucleation. At the end of drying, the film formation is created from a disordered structure, characterised by entangled and closely packed chains [22]. After drying, the prepared films were then removed from the moulds and kept in a desiccator for another $24 \mathrm{~h}$ to eliminate moisture [23]. 


\subsection{Determination of $\mathrm{pH}$ and thickness}

$\mathrm{pH}$ values of gelatin, gelatin-glycerol, gelatin-sorbitol and gelatin-glycerol/sorbitol film-forming solutions were measured using a $\mathrm{pH}$ metre (Hanna Instruments, China) [24]. Thickness measurements were taken from five different points of the film samples using a digital thickness gauge [25].

\subsection{Determination of tensile strength and elongation}

For the determination of tensile strength and elongation, test samples were prepared by cutting $2 \times 12 \mathrm{~cm}$ strips. Thickness measurement was taken from three different points of the strips and the average value was recorded. Tensile strength and elongation were measured using a Shimadzu AG-X tensile tester [14].

\subsection{Determination of transmittance}

Film transparency was taken using a Konica Minolta colorimetric spectrophotometer [26].

\subsection{Fourier transform infrared spectroscopy}

The spectra of the gelatin films were taken using a DTGSKBR detector of the Agilent 600-IR Series Fourier transform infrared spectroscopy-attenuated total reflectance (FTIR-ATR) equipment at room temperature. The films were placed on a crystal cell, and the cell was clamped into a slot of the FTIR spectrometer. FTIR spectra were recorded in the range of $500-4000 \mathrm{~cm}^{-1}$. Automatic signal acquisition was collected in 32 scans with a resolution of $4 \mathrm{~cm}^{-1}$, and these were compared to a background spectrum recorded from a clean blank cell [27].

\subsection{Scanning electron microscopy}

Scanning electron microscopy (SEM) works on the basis of scanning the surface with high-energy electrons that focalize a very small area. In SEM, the material was examined using a thin electron beam created in a vacuum environment and focused with electromagnetic lenses to create a high-resolution image [28]. In this study, the SEM images of the film samples were taken using a Zeiss Brand MA10 model scanning electron microscope with $\times 5$ magnification.

\subsection{Statistical analysis}

One-way analysis of variance (One-way ANOVA) following by Tukey's test as post hoc used to compare means at $5 \%$ significance level among different samples [20].

\section{Results and discussion}

\subsection{Gelatin viscosity and material profile}

Type $B$ bovine gelatin samples with viscosity of $2.5,3.0$ and $3.5 \mathrm{cP}$ and gel strength of 210,240 and 270 bloom were used. The chemical properties of gelatin used in the study are given in Table 1.

\subsection{Viscosity of film solutions}

Figure 1 shows the effects of different variables on the film solution viscosity characteristic. The results show that the viscosity of the solution prepared with $3.5 \mathrm{CP}$ viscosity gelatin has the highest film solution viscosity (Fig. 1d). Morever, as a result of the Tukey test $(p<0,05)$ the effect of gelatin viscosity on film solution viscosity is more effective than other parameters (Fig. 1a, b, c).

The increase in gelatin concentration increases the viscosity of the film solution due to the intermolecular cross-bonding ability of gelatin molecules. Gelatin concentrations of $5.5 \%$ and $10 \%$ has higher viscosity than the $1 \%$ concentration. In addition, it was found that using glycerol and sorbitol together and in equal proportions has a significant positive effect on film solution viscosity (Fig. 1C).

Polyols such as sorbitol and glycerol are potent plasticizers due to their capability to reduce internal hydrogen bonding while improving intermolecular spacing [29]. Depending on the aqueous environmental state and the distribution of the different kinds of functional groups, the overall protein-polysaccaride interaction can be net attractive or net repulsive [30].

\subsection{Thickness, $\mathrm{pH}$ and trasmittance of films}

The thickness of biodegradable films is mostly related to the gelatin/plasticizer concentration and solution's viscosity. As the amount of protein increases, the film thickness is expected to increase with an increase of solid matter [31]. Film thickness has an effect on tensile strength, water vapour permeability and unit density properties [32]. Thickness values of the gelatin-glycerol, gelatin-sorbitol and gelatin-glycerol/sorbitol film-forming solutions were in the range of $0.015-0.19,0.02-0.23$ and $0.13-0.18 \mathrm{~mm}$, respectively. With the use of a constant amount of gelatin and plasticizer, the film thickness of the high-viscosity solution was higher than that of the other samples.

$\mathrm{pH}$ measurements were performed on film forming solutions via $\mathrm{pH}$ meter. $\mathrm{pH}$ values of the gelatin-glycerol, gelatin-sorbitol and gelatin-gylcerol/sorbitol film forming 


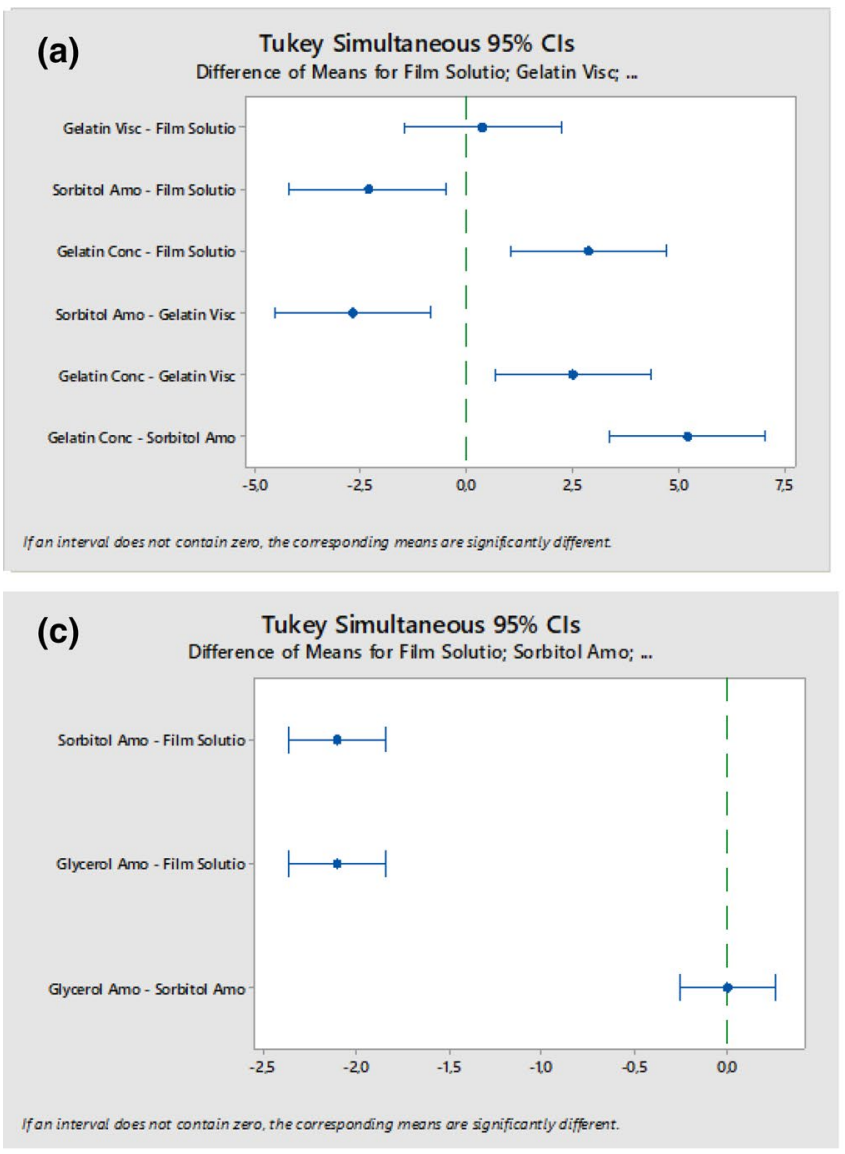

Fig. 1 a Tukey pairwise comparisons of gelatin viscosity, gelatin concentration, sorbitol amount on film solution viscosity, b Tukey pairwise comparisons of gelatin viscosity, gelatin concentration,

solutions were in the range of $5.82-5.90,5.59-5.71$ and $5.66-5.84$, recpectively.

Transmittance measurements were performed using a colorimetric spectrophotometer at $620 \mathrm{~nm}$ in response to black and white objects. The results showed that there were no significant differences in the level of transmittance.

\subsection{Tensile strength and elongation of films}

Figure 2 shows the effects of different variables on the film tensile strength properties. The results showed that tensile strength of films varied between 0 and $25.27 \mathrm{~N} / \mathrm{mm}^{2}$. Consequently, it was determined that gelatin viscosity was not the main effect on tensile strength. When the Tukey test graphics (Figs. 2a, b, c) were examined, it was determined that the increase in viscosity, increased the tensile strength when the gelatin concentration increased in all glycerol, sorbitol and combined trials.

The highest tensile strength was obtained with $3.5 \mathrm{cP}$ viscosity and $\% 5.5$ gelatin concentration. The increase of

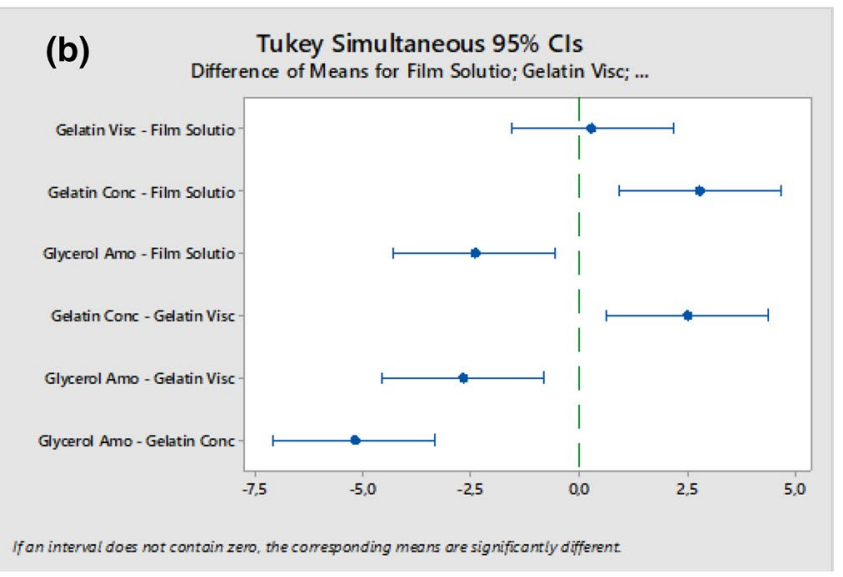

Individual Value Plot of Film Solution Viscosity vs Gelatin Viscosity (cp)

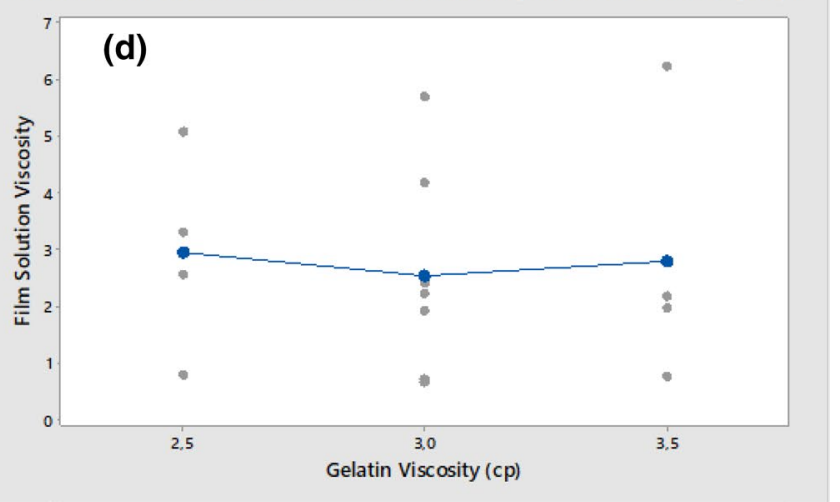

glycerol amount on film solution viscosity, c Tukey pairwise comparisons of sorbitol and glycerol amounts on film solution viscosity, d Individual value plot of film solution vs gelatin viscosity

glycerol amount has positive effect on tensile strength while increasing gelatin viscosity. However, the effect of the glycerol amount on tensile strength is negligible.

Figure 3 showed that elongation values varied between $3.21 \%$ and $258.41 \%$. When Tukey test graphics (Fig. 3a, b, c) were examined, the results show that the effect of glycerol, sorbitol and gelatin concentrations on the elongation amount was the same as gelatin viscosity. Additionally, the increase in gelatin viscosity negatively affects the elongation percentage of films. Since glycerol are highly hygroscopic, an increase in the plastizer amount used with fixed gelatin concentration increases the plasticising efficiency, which decreases the elongation [33]. Sorbitol also presented an apparent protecting effect against the helix-coil transition, decreasing the formation of junctions responsible for the crystallinity of gelatin observed through the reduction of the enthalpy of the sol-gel transition.

The effects of using glycerol and sorbitol as plasticizers in varying proportions on the mechanical properties of the films can be seen in Fig. 4 The amount of glycerol and sorbitol used was $0.5 \%, 0.4 \%, 0.3 \%$ and $0.2 \%$ while keeping 


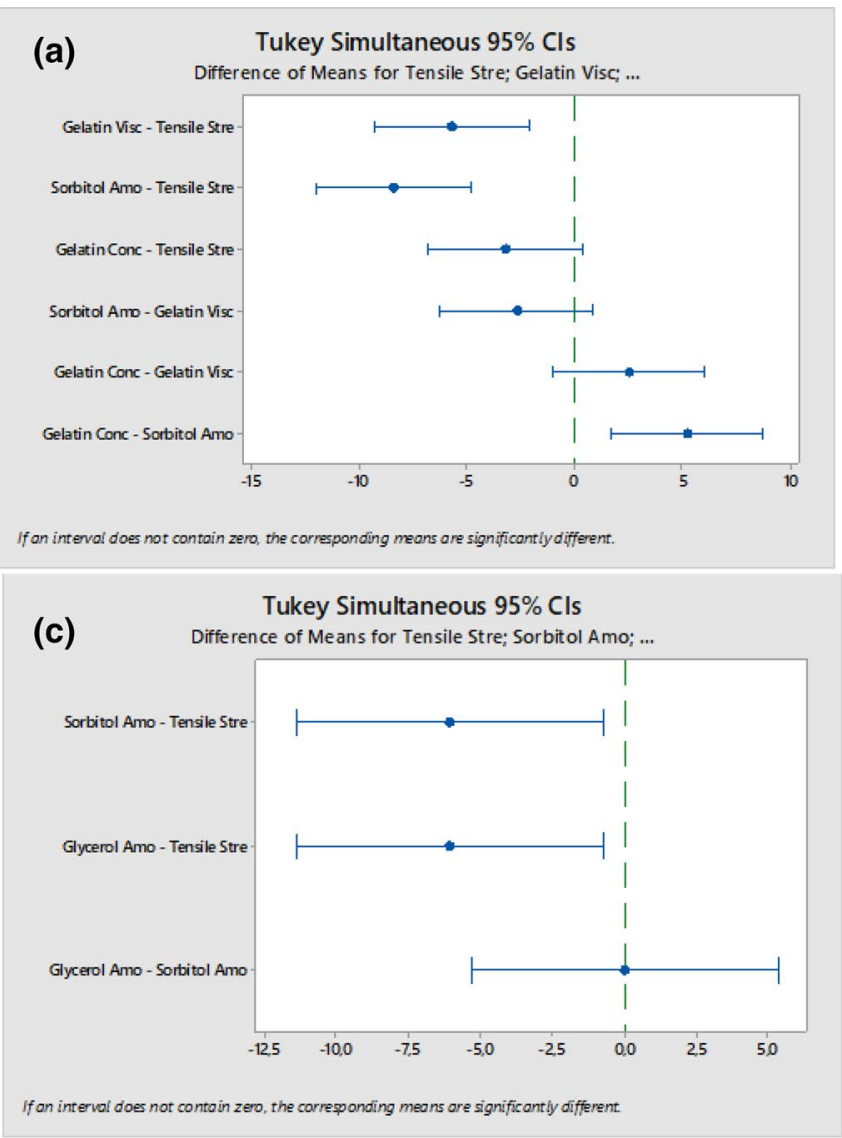

Fig. 2 a Tukey pairwise comparisons of gelatin viscosity, gelatin concentration, sorbitol amount on tensile strenght, b Tukey pairwise comparisons of gelatin viscosity, gelatin concentration, glyc-

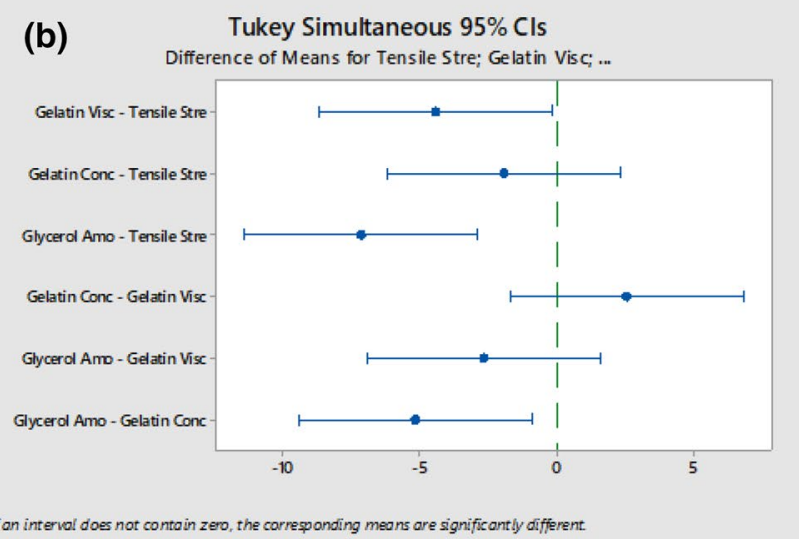

Individual Value Plot of Tensile Strenght ( $\mathrm{N} / \mathrm{mm} 2)$ vs Gelatin Viscosity (cp)

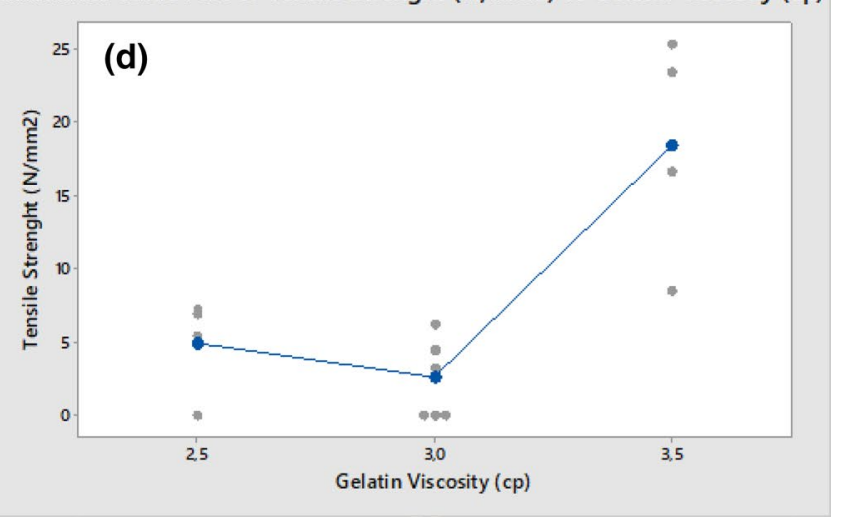

erol amount on tensile strenght, $\mathbf{c}$ Tukey pairwise comparisons of sorbitol and glycerol amounts on on tensile strenght, $\mathbf{d}$ Individual value plot of tensile strenght vs gelatin viscosity

and $\mathrm{C}-\mathrm{N}$ stresses as well as the vibrations of $\mathrm{CH}_{2}$ groups in the glycerol spine and pyrroline side chains [35]. The peak of $\mathrm{N}, \mathrm{N}$-disubstituted amides shifts from $1659 \mathrm{~cm}^{-1}$ for pure gelatin to a lower wave number with an increase in glycerol content, and it shifts to $1650 \mathrm{~cm}^{-1}$ for gelatin-glycerol. The shift of $\mathrm{N}, \mathrm{N}$-disubstituted amides to a lower wavenumber suggests an increase in average strength of the hydrogen bond because of the disruption of $\mathrm{C}=\mathrm{O} \ldots . \mathrm{H}-\mathrm{N}$ hydrogen bonds in gelatin and the formation of new stronger $\mathrm{C}=\mathrm{O} \ldots . \mathrm{H}-\mathrm{O}$ hydrogen bonds between gelatin and glycerol (Ramos OL et al., 2013). In the glycerol-added gelatin film, the characteristic $\mathrm{C}-\mathrm{O}$ stretching band of glycerol was clearly observed at $1045-1050 \mathrm{~cm}^{-1}[36,37]$ (Fig. 5).

For gelatin-sorbitol composite films, Amid A and Amid $B$ bands are seen at $3300-3100 \mathrm{~cm}^{-1}$. These bonds are related to the stress vibrations of the $\mathrm{N}-\mathrm{H}$ groups. The Amid I band seen at $1650 \mathrm{~cm}^{-1}$ is derived from the tensile vibrations of the $\mathrm{C}=\mathrm{O}$ peptide [34]. Amid I band seen at $1550 \mathrm{~cm}^{-1}$ is caused by $\mathrm{N}-\mathrm{H}$ bending due to $\mathrm{C}-\mathrm{N}$ tensile vibrations. The most important peaks for sorbitol are at Amid III band seen at $1250 \mathrm{~cm}^{-1}$ is also attributed to $\mathrm{N}-\mathrm{H}$ 

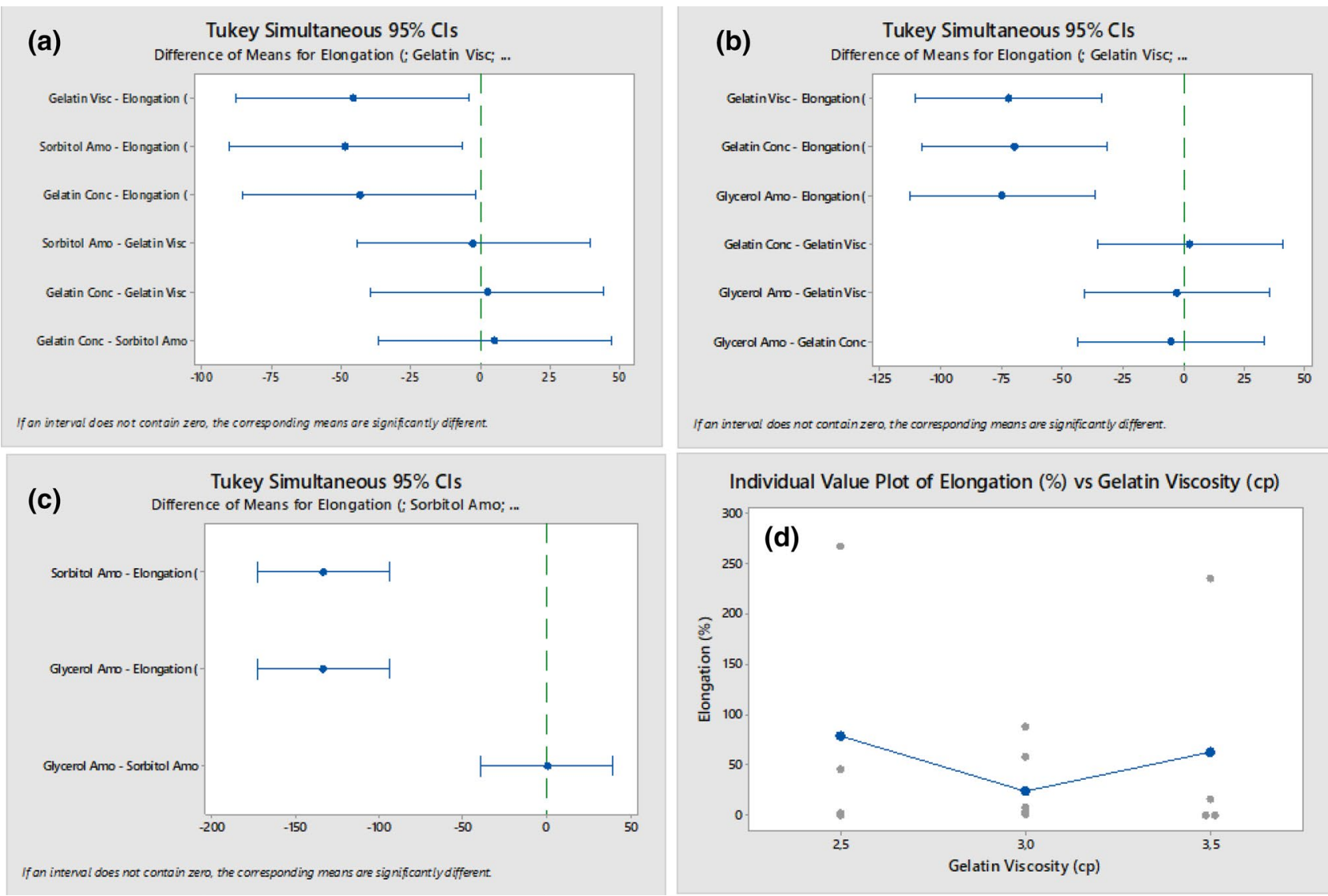

If an intervel does not cantain zera, the carresponding means are significantly different.
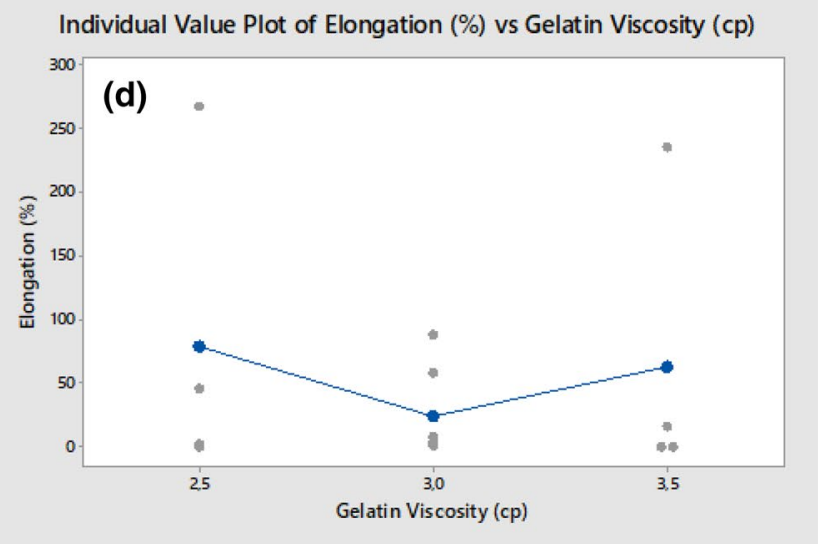

Fig. 3 a Tukey pairwise comparisons of gelatin viscosity, gelatin concentration, sorbitol amount on elongation, b Tukey pairwise comparisons of gelatin viscosity, gelatin concentration, glycerol

amount on elongation, c Tukey pairwise comparisons of sorbitol and glycerol amounts on on elongation, $\mathbf{d}$ Individual value plot of elongation vs gelatin viscosity

Fig. 4 Tensile strength and elongations of gelatin-based film plasticised with glycerolsorbitol combination

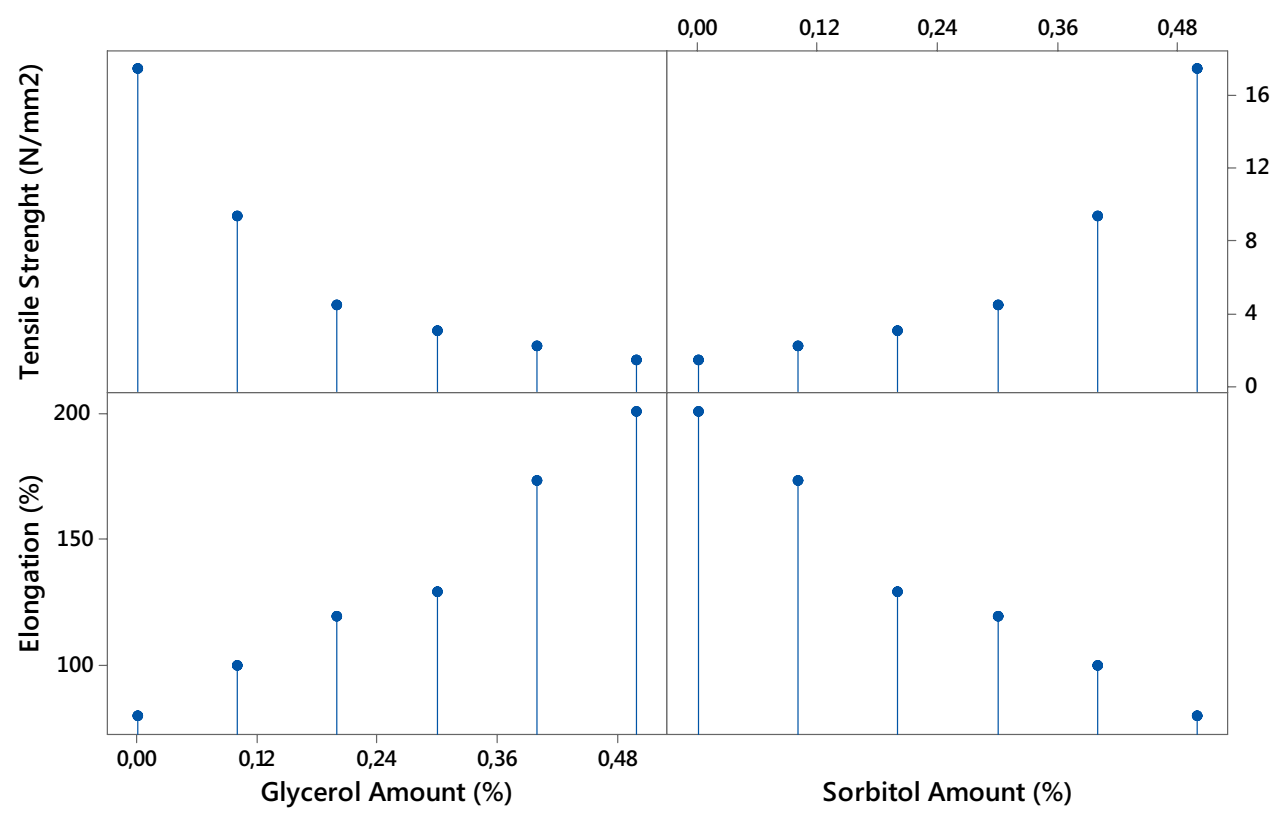


Fig. 5 FTIR plot of gelatinglycerol film

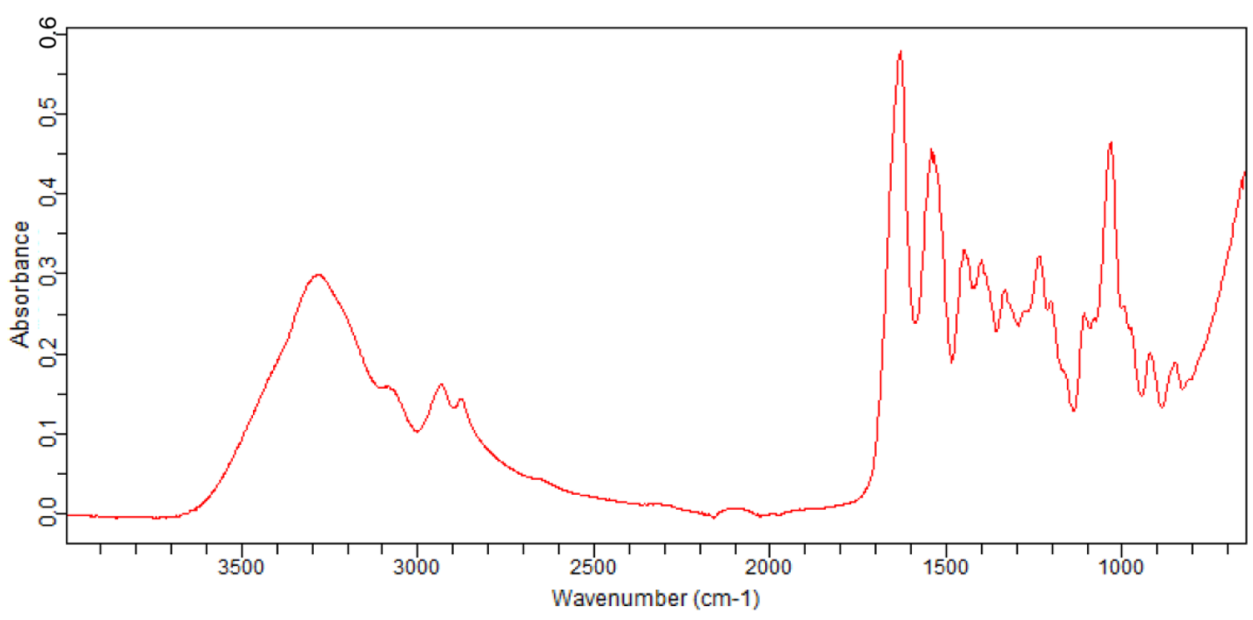

Fig. 6 FTIR plot of gelatinsorbitol film

Fig. 7 FTIR plot of gelatinglycerol/sorbitol film
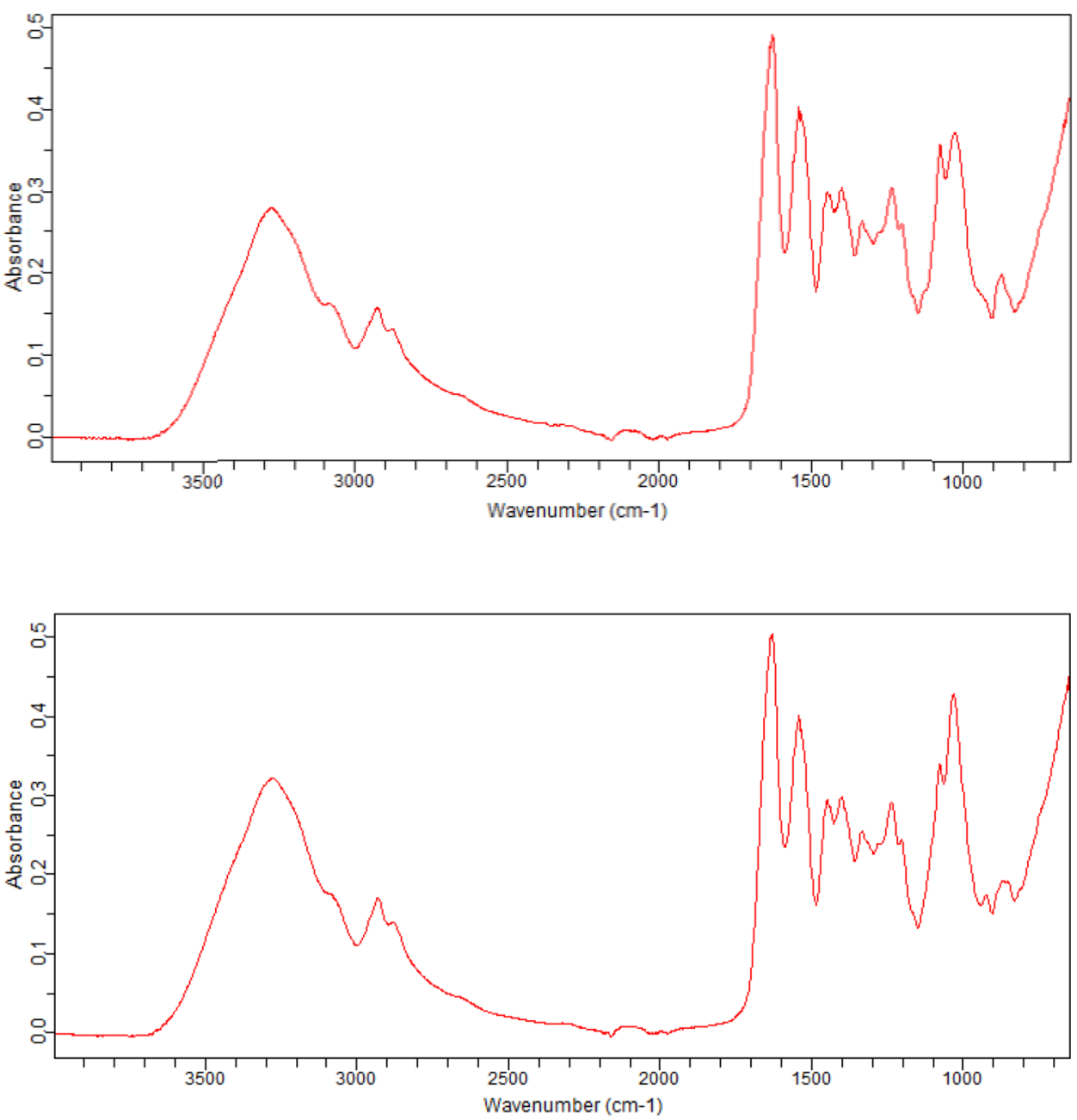

For gelatin-glycerol/sorbitol composite films, Amid A and Amid $B$ bands are seen at $3300-3100 \mathrm{~cm}^{-1}$. These bands are related to the stress vibrations of the $\mathrm{N}-\mathrm{H}$ groups. The Amid I band seen at $1650 \mathrm{~cm}^{-1}$ is derived from the tensile vibrations of the $C=O$ peptide [34]. Amid I band seen at $1550 \mathrm{~cm}^{-1}$ is
$890,1046,1084$ and $1411 \mathrm{~cm}^{-1}$. The characteristic peak for sorbitol is the peak seen at $890 \mathrm{~cm}^{-1}$. In addition, a flat peak appears at $3300 \mathrm{~cm}-1$ due to the $\mathrm{OH}$ groups in the structure of sorbitol and the $\mathrm{OH}$ peak from gelatin [38] (Fig. 6). 
Fig. 8 Gelatin-based films SEM images

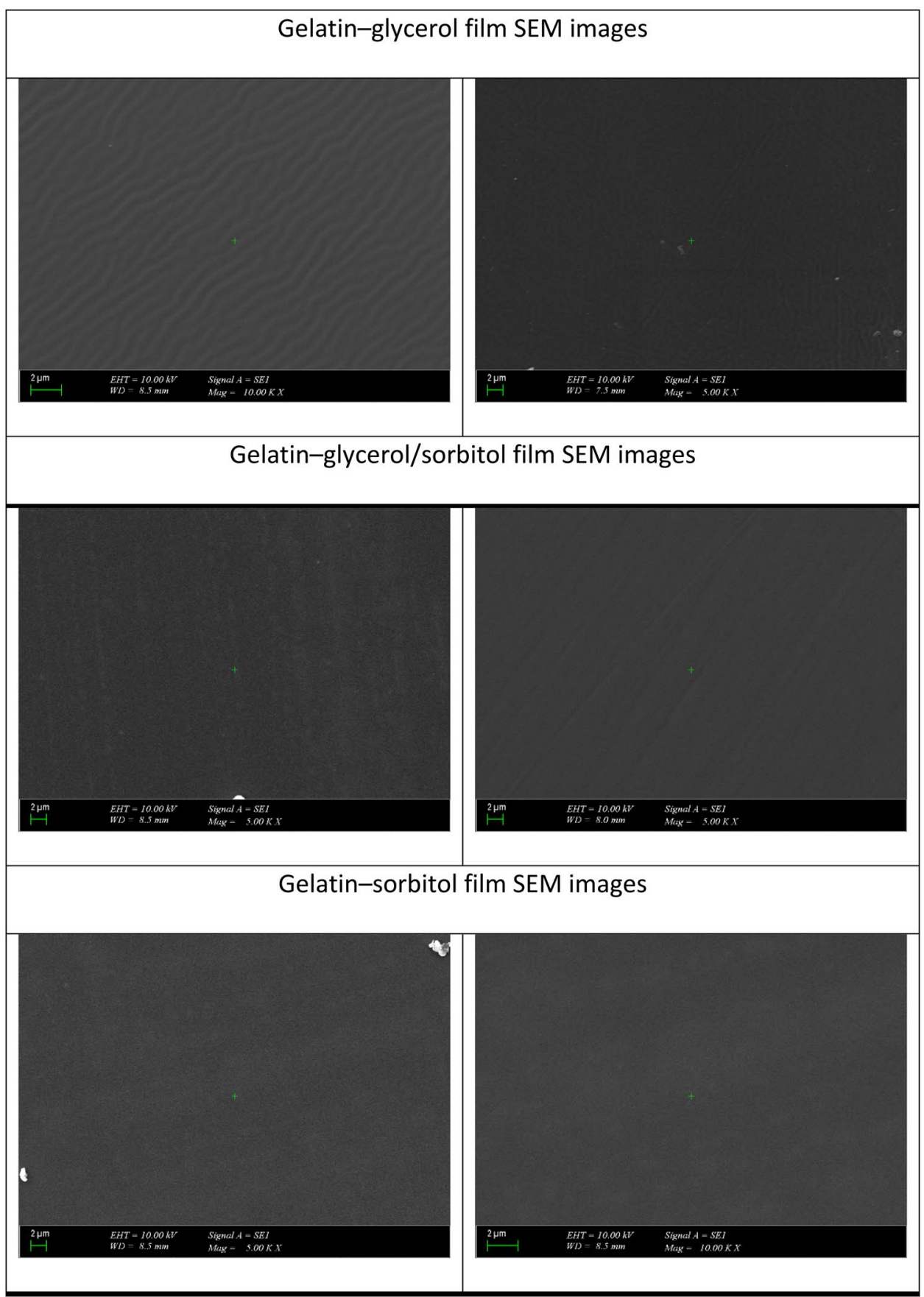

caused by $\mathrm{N}-\mathrm{H}$ bending due to $\mathrm{C}-\mathrm{N}$ tensile vibrations. Amid III band seen at $1250 \mathrm{~cm}^{-1}$ is also attributed to $\mathrm{N}-\mathrm{H}$ and $\mathrm{C}-\mathrm{N}$ stresses as well as the vibrations of $\mathrm{CH}_{2}$ groups in the glycerol spine and pyrroline side chains. The most important peaks for sorbitol are at $890,1046,1084$ and $1411 \mathrm{~cm}^{-1}$. The characteristic peak for sorbitol is the peak seen at $890 \mathrm{~cm}^{-1}$. In addition, because of the $\mathrm{OH}$ groups in the structure of sorbitol and the $\mathrm{OH}$ peak from gelatin, a flat peak appears at $3300 \mathrm{~cm}^{-1}$ (Fig. 7).
When the gelatin-glycerol/sorbitol composite structure was examined by FTIR spectroscopy, gelatin-glycerol and gelatin-sorbitol have similar FTIR structures. However, a double peak is observed for gelatin-glycerol at $800-1000 \mathrm{~cm}^{-1}$ while a single peak is observed for gelatin-sorbitol. In the gelatin-glycerol/sorbitol composite FTIR plot, there are double peaks at $800-1000 \mathrm{~cm}^{-1}$ that reveal the structure difference, but the peak at $890 \mathrm{~cm}^{-1}$, which is the characteristic peak for sorbitol, is more common. These results indicate that the gelatin-sorbitol/glycerol composite was obtained. 
Even though glycerol and sorbitol are different types of plasticizers, both classified as polyols. Furthermore, the existence of aliphatic of alcohol in the plasticized film were shown defining due to the availability of the plasticizer [39].

The displacements were arised with the increased in entirety and sharper peaks in comparing the control film with the film incorporated with the plasticizers due to the contribution of-OH group from the plasticizers. The peaks generally correspond to the- $\mathrm{NH}$ stretching coupled with hydrogen bond which responsible with the width [40].

\subsection{SEM}

SEM images were taken by selecting three samples from the gelatin-glycerol, gelatin-sorbitol and gelatin-glycerol/sorbitol films and the surface appearance was successful. All film samples were transparent, but some have a slightly yellow-to-brown appearance, although they were quite translucent. In terms of transparency, no significant difference was observed among the samples. SEM micrographs of films using sorbitol, glycerol and combined plasticisers is shown in Fig. 8. With the images obtained, the films look clean and smooth.

The excellent structural entirety of the film is similar to the currently used transparent packaging products. This result showed that a successive matrix structure of the film component was formed [41].

\section{Conclusion}

In the presence of sorbitol and glycerol as plasticisers, it was investigated how varying gelatin viscosities affects the chemical, morphological and mechanical properties of gelatin-based films. As a result of the gelatin-plasticiser combination studies, a durable film structure can be obtained with gelatin viscosity $3 \mathrm{cP}, 5.5 \%$ gelatin, $0.1 \%$ glycerol and $0.4 \%$ sorbitol formulation. The results obtained in the studies conducted show that gelatin viscosity affects the film structures. SEM results shows that gelatin and glycerol concentrations affect the surface morphology of the film. Increasing or decreasing both variables causes the surface to shrink with temperature. Apart from this, it is possible to obtain acceptable smooth and flat surfaces by using glycerol and sorbitol under optimal conditions. It has been concluded that gelatin films can be a good and sustainable alternative to meet the increasing need for bio packaging. However, advanced studies should be developed to improve the shelf life and degradability of gelatin-based films.
Acknowledgements The authors wish to express their thanks to the Halavet Gelatin San. A.Ş and Sunar Mısır Entegre Tesisleri San. ve Tic. A.Ş for their support given to this research.

Data Availability The raw/processed data required to reproduce these findings cannot be shared at this time as the data also forms part of an ongoing study.

\section{Compliance with ethical standards}

Conflict of interest The authors declare that they have no confict of interest.

Open Access This article is licensed under a Creative Commons Attribution 4.0 International License, which permits use, sharing, adaptation, distribution and reproduction in any medium or format, as long as you give appropriate credit to the original author(s) and the source, provide a link to the Creative Commons licence, and indicate if changes were made. The images or other third party material in this article are included in the article's Creative Commons licence, unless indicated otherwise in a credit line to the material. If material is not included in the article's Creative Commons licence and your intended use is not permitted by statutory regulation or exceeds the permitted use, you will need to obtain permission directly from the copyright holder. To view a copy of this licence, visit http://creativecommons .org/licenses/by/4.0/.

\section{References}

1. Cui H, Surendhiran D, Li C, Lin L (2020) Biodegradable zein active film containing chitosan nanoparticle encapsulated with pomegranate peel extract for food packaging. Food Packag Shelf Life 24:100511. https://doi.org/10.1016/j.fpsl.2020.100511

2. Arikan EB, Ozsoy HD (2015) A review investigation of bioplastics. J Civ Eng Archit 9:188-192. https://doi.org/10.17265 /1934-7359/2015.02.007

3. Haghighi H, Licciardello F, Fava P, Siesler HW, Pulvirenti A (2020) Recent advances on chitosan-based films for sustainable food packaging applications. Food Packag Shelf Life 26:100551. https ://doi.org/10.1016/j.fpsl.2020.100551

4. Ahmad T, Ismail A, Ahmad SA, Khalil KA, Kumar Y, Adeyemi KD, Sazili AQ (2017) Recent advances on the role of process variables affecting gelatin yield and characteristics with special reference to enzymatic extraction: a review. Food Hydrocoll 63:85-96. https://doi.org/10.1016/j.foodhyd.2016.08.007

5. Chen H, Wang J, Cheng Y, Wang C, Liu H, Bian H, Pan Y, Sun J, Han W (2019) Application of protein-based films and coatings for food packaging: a review. Polymers (Basel) 11:1-32. https:// doi.org/10.3390/polym11122039

6. Zubair M, Ullah A (2020) Recent advances in protein derived bionanocomposites for food packaging applications. Crit Rev Food Sci Nutr 60:406-434. https://doi.org/10.1080/10408 398.2018.1534800

7. Suhag R, Kumar N, Petkoska AT, Upadhyay A (2020) Film formation and deposition methods of edible coating on food products: a review. Food Res Int 136:109582. https://doi. org/10.1016/j.foodres.2020.109582

8. Tuan Zainazor TC, Fisal A, Goh EG, Che Sulaiman NF, Sarbon NM (2020) Emerging of bio-nano composite gelatine-based film as 
bio-degradable food packaging: a review. Food Res 4:944-956. https://doi.org/10.26656/fr.2017.4(4).365

9. Abedinia A, Mohammadi Nafchi A, Sharifi M, Ghalambor P, Oladzadabbasabadi N, Ariffin F, Huda N (2020) Poultry gelatin: characteristics, developments, challenges, and future outlooks as a sustainable alternative for mammalian gelatin. Trends Food Sci Technol 104:14-26. https://doi.org/10.1016/j.tifs.2020.08.001

10. Arpi N, Fahrizal M, Hardianti E (2018) Preparation and characterization of biodegradable film based on skin and bone fish gelatin. IOP Conf Ser Earth Environ Sci 207:012050. https://doi. org/10.1088/1755-1315/207/1/012050

11. Kuan YH, Nafchi AM, Huda N, Ariffin F, Karim AA (2017) Comparison of physicochemical and functional properties of duck feet and bovine gelatins. J Sci Food Agric 97:1663-1671. https://doi. org/10.1002/jsfa.7970

12. Nik Muhammad NA, Huda N, Karim AA, Mohammadi Nafchi A (2018) Effects of acid type extraction on characterization and sensory profile of duck feet gelatin: towards finding bovine gelatin alternative. J Food Meas Charact 12:480-486. https:// doi.org/10.1007/s11694-017-9661-8

13. Alias SA, Mhd Sarbon N (2019) Rheological, physical, and mechanical properties of chicken skin gelatin films incorporated with potato starch. npj Sci Food 3:26. https://doi.org/10.1038/ s41538-019-0059-3

14. Ramos M, Valdés A, Beltrán A, Garrigós M (2016) Gelatin-based films and coatings for food packaging applications. Coatings 6:41. https://doi.org/10.3390/coatings6040041

15. Hosseini S, Gómez-Guillén M (2018) A state-of-the-art review on the elaboration of fish gelatin as bioactive packaging: special emphasis on nanotechnology-based approaches. Trends Food Sci Technol 79:125-135. https://doi.org/10.1016/j. tifs.2018.07.022

16. Imre B, Pukánszky B (2013) Compatibilization in bio-based and biodegradable polymer blends. Eur Polym J 49:1215-1233. https ://doi.org/10.1016/j.eurpolymj.2013.01.019

17. Jahit IS, Nazmi NNM, Isa MIN, Sarbon NM (2016) Preparation and physical properties of gelatin/CMC/chitosan composite films as affected by drying temperature. Int Food Res J 23:1068-1074

18. GMIA (2019) Standard testing methods for edible gelatin. http:// www.gelatin-gmia.com/

19. Kim TK, Ham YK, Shin DM, Kim HW, Jang HW, Kim YB, Choi YS (2020) Extraction of crude gelatin from duck skin: effects of heating methods on gelatin yield. Poult Sci 99:590-596. https ://doi.org/10.3382/ps/pez519

20. Arezoo E, Mohammadreza E, Maryam M, Abdorreza MN (2020) The synergistic effects of cinnamon essential oil and nano TiO2 on antimicrobial and functional properties of sago starch films. Int J Biol Macromol 157:743-751. https://doi.org/10.1016/j.ijbio mac.2019.11.244

21. Al-Hassan AA, Norziah MH (2012) Starch-gelatin edible films: water vapor permeability and mechanical properties as affected by plasticizers. Food Hydrocoll 26:108-117. https:// doi.org/10.1016/j.foodhyd.2011.04.015

22. Aguirre-Alvarez G, Pimentel-González DJ, Campos-Montiel RG, Foster T, Hill SE (2011) The effect of drying temperature on mechanical properties of pig skin gelatin films. CYTA-J Food 9:243-249. https://doi.org/10.1080/19476337.2010.523902

23. Andreuccetti C, Carvalho R, Grosso C (2009) Effect of hydrophobic plasticizers on functional properties of gelatin-based films. Food Res Int 42:1113-1121. https://doi.org/10.1016/j.foodr es.2009.05.010

24. Tao Z, Weng WY, Cao MJ, Liu GM, Su WJ, Osako K, Tanaka M (2015) Effect of blend ratio and $\mathrm{pH}$ on the physical properties of edible composite films prepared from silver carp surimi and skin gelatin. J Food Sci Technol 52:1618-1625. https://doi. org/10.1007/s13197-013-1186-5
25. Wu X, Liu Y, Wang W, Han Y, Liu A (2017) Improved mechanical and thermal properties of gelatin films using a nano inorganic filler. J Food Process Eng 40:1-10. https://doi.org/10.1111/ jfpe.12469

26. Pathare PB, Opara UL, Al-Said FAJ (2013) Colour measurement and analysis in fresh and processed foods: a review. Food Bioprocess Technol 6:36-60. https://doi.org/10.1007/s1194 7-012-0867-9

27. Nur Hanani ZA, Roos YH, Kerry JP (2011) Fourier transform Infrared (FTIR) spectroscopic analysis of biodegradable gelatin films immersed in water. 11th Int Congr Eng Food 5:6-9

28. Belirgen $M Z$ (2014) Doğal ve yapay mezokristaller üzerine bir çalışma: sentez. Yapısal Karakterizasyon ve Fiziksel Özellik Araştırmaları, Yüksek Lisans Tezi, Nanoteknoloji ve Nanotıp Anabilim Dalı, p 105s

29. Lieberman ER, Gilbert SG (2007) Gas permeation of collagen films as affected by cross-linkage, moisture, and plasticizer content. J Polym Sci Polym Symp 41:33-43. https://doi.org/10.1002/ polc.5070410106

30. Dickinson E (1998) Stability and rheological implications of electrostatic milk protein-polysaccharide interactions. Trends Food Sci Technol 9:347-354. https://doi.org/10.1016/S0924 -2244(98)00057-0

31. Fakhouri FM, Martelli SM, Caon T, Velasco Jl, Mei LHI (2015) Edible films and coatings based on starch/gelatin: film properties and effect of coatings on quality of refrigerated red crimson grapes. Postharvest Biol Technol 109:57-64. https://doi. org/10.1016/j.postharvbio.2015.05.015

32. Fadini AL, Rocha FS, Alvim ID, Sadahira MS, Queiroz MB, Alves RMV, Silva LB (2013) Mechanical properties and water vapour permeability of hydrolysed collagen-cocoa butter edible films plasticised with sucrose. Food Hydrocoll 30:625-631. https:// doi.org/10.1016/j.foodhyd.2012.08.011

33. Vanin FM, Sobral PJA, Menegalli FC, Carvalho RA, Habitante AMQB (2005) Effects of plasticizers and their concentrations on thermal and functional properties of gelatin-based films. Food Hydrocoll 19:899-907. https://doi.org/10.1016/j.foodh yd.2004.12.003

34. Riaz T, Zeeshan R, Zarif F, llyas K, Muhammad N, Safi SZ, Rahim A, Rizvi SAA, Rehman IU (2018) FTIR analysis of natural and synthetic collagen. Appl Spectrosc Rev 53:703-746. https://doi. org/10.1080/05704928.2018.1426595

35. Belbachir K, Noreen R, Gouspillou G, Petibois C (2009) Collagen types analysis and differentiation by FTIR spectroscopy. Anal Bioanal Chem 395:829-837. https://doi.org/10.1007/s0021 6-009-3019-y

36. Bergo P, Sobral PJA (2007) Effects of plasticizer on physical properties of pigskin gelatin films. Food Hydrocoll 21:1285-1289. https://doi.org/10.1016/j.foodhyd.2006.09.014

37. Peña C, Mondragon G, Algar I, Mondragon I, Martucci J, Ruseckaite R (2013) Gelatin films: renewable resource for food packaging. In Gökhan B (ed) Gelatin: production, applications and health implications. Nova Science Publishers, NY, pp 1-15

38. De Castro E, Cassella R (2016) Direct determination of sorbitol and sodium glutamate by attenuated total reflectance fourier transform infrared spectroscopy (ATR-FTIR) in the thermostabilizer employed in the production of yellow-fever vaccine. Talanta 152:33-38. https://doi.org/10.1016/j.talanta.2016.01.054

39. Muyonga JH, Cole CGB, Duodu KG (2004) Characterisation of acid soluble collagen from skins of young and adult Nile perch (Lates niloticus). Food Chem 85:81-89. https://doi.org/10.1016/j. foodchem.2003.06.006

40. Azmi NS, Basha RK, Tajul Arifin NN, Othman SH, Mohammed MAP (2020) Functional properties of tilapia's fish scale gelatin film: effects of different type of plasticizers. Sains Malaysiana 49:2221-2229. https://doi.org/10.17576/jsm-2020-4909-19 
41. Rawdkuen S, Suthiluk P, Kamhangwong D, Benjakul S (2012) Mechanical, physico-chemical, and antimicrobial properties of gelatin-based film incorporated with catechin-lysozyme. Chem Cent J 6:1. https://doi.org/10.1186/1752-153X-6-131
Publisher's Note Springer Nature remains neutral with regard to jurisdictional claims in published maps and institutional affiliations. 